\title{
Do Relaxin Levels Impact Hip Injury Incidence in Women? A Scoping Review
}

OPEN ACCESS

Edited by: Sadiq Umar,

University of Illinois at Chicago, United States

Reviewed by: Liping Zhou,

Capital Medical University, China Yixuan Deng, Chongaing Medical University, China

${ }^{*}$ Correspondence: Emily A. Parker Emily-A-Parker@uiowa.edu

${ }^{\text {t}}$ These authors have contributed equally to this work

Specialty section: This article was submitted to Bone Research, a section of the journal

Frontiers in Endocrinology

Received: 02 December 2021 Accepted: 05 January 2022 Published: 04 February 2022

Citation:

Parker EA, Meyer AM, Goetz JE, Willey MC and Westermann RW

(2022) Do Relaxin Levels Impact Hip Injury Incidence in Women? A Scoping Review.

Front. Endocrinol. 13:827512. doi: 10.3389/fendo.2022.827512

\author{
Emily A. Parker ${ }^{1 *}$, Alex M. Meyer ${ }^{1 \dagger}$, Jessica E. Goetz ${ }^{1,2 \dagger}$, Michael C. Willey ${ }^{1 \dagger}$ \\ and Robert W. Westermann ${ }^{1+}$ \\ ${ }^{1}$ Department of Orthopedics and Rehabilitation, University of lowa Hospitals and Clinics, lowa City, IA, United States, \\ 2 Orthopedic Biomechanics Laboratories, Department of Orthopedics and Rehabilitation, University of lowa Hospitals and \\ Clinics, lowa City, IA, United States
}

Purpose: The aim of this review is to assess the current evidence regarding the impact of relaxin on incidence of soft tissue hip injuries in women.

Methods: A trained research librarian assisted with searches of PubMed, Embase, CINAHL, and SPORTDiscus, with a preset English language filter. The review was completed per the Joanna Briggs Institute (JBI) Manual for Evidence Synthesis methodology. Included studies required assessment of relaxin effects on musculoskeletal health, pelvic girdle stability, or hip joint structures in human subjects. Letters, texts, and opinion papers were excluded.

Results: Our screen yielded 82 studies. Molecularly, relaxin activates matrix metalloproteinases (MMPs) including collagenases MMP-1/-13 and gelatinases MMP2/-9 to loosen pelvic ligaments for parturition. However, relaxin receptors have also been detected in female periarticular tissues, such as the anterior cruciate ligament, which tears significantly more often during the menstrual cycle peak of relaxin. Recently, high concentrations of relaxin-activated MMP-9 receptors have been found on the acetabular labrum; their expression upregulated by estrogen.

Conclusions: Menstrual cycle peaks of relaxin activate MMPs, which locally degrade collagen and gelatine. Women have relaxin receptors in multiple joints including the hip and knee, and increased relaxin correlates with increased musculoskeletal injuries. Relaxin has paracrine effects in the female pelvis on ligaments adjacent to hip structures, such as acetabular labral cells which express high levels of relaxin-targeted MMPs. Therefore, it is imperative to investigate the effect of relaxin on the hip to determine if increased levels of relaxin are associated with an increased risk of acetabular labral tears.

Keywords: hip preservation, sex differences, female reproductive cycle, relaxin, sex-based, menstrual cycle hormones, hormonal contraceptives 


\section{INTRODUCTION}

Female athletes still face sex-based disparity in sports-related injury with significantly lower likelihood of a healthy career. One in five female collegiate athletes will suffer an anterior cruciate ligament (ACL) injury in college (1-3). ACL ruptures are a more evident, more thoroughly researched female-predominant injury (4-6); females in this age group are also more likely to undergo surgical treatment for athletic hip injuries. Multiple factors contribute to the female predominance of ACL injuries, including neuromuscular discrepancies and fluctuating levels of reproductive hormones (7). Hormonal research has recently identified a promising target: relaxin $(1,7-10)$. This has not been investigated in relation to young athletic hip conditions.

Relaxin cycles with other menstrual hormones and weakens collagen in target tissues such as the pubic symphysis (1, 9-14). While necessary for parturition, this can be detrimental outside of the reproductive system (15-17). Multiple studies correlate relaxin peaks with female ACL tears $(1,9)$. However, despite large-scale relaxin synthesis in the pelvis, and a known paracrine activity profile, there is a paucity of literature assessing if relaxin levels correlate with another female-predominant lower extremity injury impacting athletes such as acetabular labral tears (18-21). If relaxin does significantly contribute to the elevated rates of both knee and hip injuries in women, further research into preventive strategies is critical.

The absence of literature regarding relaxin vs. hip injuries necessitated a scoping review to appraise available information on factors related to relaxin versus hip injury, and to identify conceptual gaps (22). This review assessed relevant literature on nanoscale, microscale, and macroscale actions of relaxin. The objective of this scoping review is to show that it is scientifically logical and medically important to further explore the potential correlation between relaxin levels and female hip injuries.

\section{METHODS}

A preliminary search of MEDLINE, the Cochrane Database of Systematic Reviews and JBI Evidence Synthesis (Joanna Briggs Institute, Adelaide, Australia) was conducted and no current or underway systematic reviews or scoping reviews on the topic were identified. The scoping review was conducted in accordance with the JBI methodology for scoping reviews (JBI Manual for Evidence Synthesis) and the Preferred Reporting Items for Systematic reviews and Meta-Analyses for Scoping Reviews (PRISMA-ScR) Checklist (Supplementary Material: Appendix 1).

\section{Types of Sources}

This scoping review considered all traditional types of papers, with the exclusion of commentaries, editorials, and opinion papers.

\section{Search Strategy}

The search strategy was developed by the authors with the assistance of a Health Sciences librarian specializing in development of database queries. The search strategy aimed to locate both published and unpublished studies ("gray literature"). An initial limited search of MEDLINE and EMBASE was undertaken to identify articles on the topic. The index terms used to describe the articles were used to develop the full search strategy, along with text words derived from the titles and abstracts of relevant articles.

The initial search strategy was developed for MEDLINE. The first search concept focused on female hormonal variations, with $\mathrm{MeSH}$ terms such as estrogens, progesterone, relaxin, and contraceptives. Text words and phrases included "cyclic hormonal variation" and "female athlete hormonal variation". The second search concept focused on non-arthritic hip pain, with $\mathrm{MeSH}$ terms such as hip dysplasia and femoroacetabular impingement. Text words and phrases included "acetabular labral tear" and "pelvic floor disorder". The full search strategy for MEDLINE can be found in the Appendix (Supplementary Material: Appendix 2).

The search strategy was then adapted for EMBASE and CINAHL. Full search strategies for these databases are available upon request. The reference list of all included sources of evidence was screened for additional source materials via SCOPUS. A filter for English language studies was used. During the screening process, the decision was made to exclude animal-only studies.

\section{Source of Evidence Selection and Data Extraction}

All identified citations were uploaded to EndNote (EndNote X9.2, Clarivate Analytics, PA, USA) and duplicates removed by a combination of software screening and manual review. Titles and abstracts were then screened by two authors independently against the inclusion criteria (Table 1). A full-text assessment was then performed to identify final inclusions. We elected to exclude animal-only studies, and include studies of pregnant women only for the pelvis and hip subsections. Any disagreements during the selection process were resolved by the senior authors.

Data was extracted by two authors, independently, with oversight from the senior authors. The data included subject demographics, concept/context, study methods, and key findings relevant to the present review questions. The data extraction approach was modified and revised as necessary. The data was documented in one or more analytical categories of relaxin effect level: cellular/molecular, systemic-musculoskeletal, pelvic structure-specific, and hip-specific.

Per scoping review protocol, critical appraisal of individual sources was not completed. The current review will not individually discuss all included studies. Discussion will address studies with novel information and/or critical concepts, which will be recorded in subject-specific tables (Tables 2-4). However, all included references are listed in Supplementary Material: Appendix 3.

\section{DATA ANALYSIS RESULTS}

Of the initial library screened, 82 articles were included for scoping review $(1,4,5,7-21,23-86)$. There was overlap between analysis categories for numerous papers; most prevalent with the subjects are of cellular/molecular and systemic-musculoskeletal effects. The effects of relaxin were discussed at the cellular/molecular level by 24 
TABLE 1 | Scoping review screening, inclusion and exclusion criteria.

- $\quad$ Adults and children

- Level I-V, unpublished ("gray") literature

- $\quad$ Systematic Reviews/Meta-Analyses

- All publication dates

- Mixed studies with animal and human subjects

- Ex) Molecular analysis of porcine and human ligaments

- Human cadaver studies

- Must address a scoping review question

- Relaxin and musculoskeletal health

- Relaxin and pelvic girdle stability

- Relaxin and hip structures studies $(10,13,16,17,23-33,58,62,68,71,76,77,80,83,84)$, and at the systemic-musculoskeletal level by 25 studies $(1,4,7-9,11,12,14$, $15,34-39,57,60,61,63,64,67,75,81,82,85)$. The pelvic structurespecific effects of relaxin were discussed by 17 studies $(21,40-51,59$, $73,74,86)$, and 9 studies focused on hip joint-specific relaxin effects $(18-21,45,52-55)$

\section{DATA PRESENTATION AND DISCUSSION}

The present review identified conceptual gaps regarding the intersection of relaxin levels and female hip injuries, and appraised available information on factors related to the topic, with review of 82 studies. Literature data was documented in conceptual categories of relaxin effects. Important/main concepts from the data assessed for each category are reported in the following sub-sections.

\section{CELLULAR/MOLECULAR EFFECTS OF RELAXIN}

\section{Basic Properties of Relaxin}

Relaxin is a peptide hormone present in both sexes, with known paracrine, autocrine, and endocrine actions. The corpus luteum synthesizes the bulk of relaxin, but the endometrium, placenta, breast tissue, and prostate have also been detected as synthesis sites. Average serum relaxin concentration (SRC) is similar between non-pregnant women and men; although women's levels peak at menstrual cycle day 21-24. As relaxin often acts in a paracrine fashion, SRC does not consistently reflect the extent of hormone activity (Table 2 ). The menstrual cycle peaks and corresponding molecular changes in the body for the three essential menstrual hormones-estrogen, progesterone, and relaxin-are depicted in Figure 1.

\section{Properties of Relaxin Receptors}

The location of relaxin family peptide receptors (RXFPs) is a sensitive indicator of physiological roles. Thus, the curiosity regarding sex-specific musculoskeletal roles of relaxin, as RXFPs are uniformly present-only in women-in the synovial lining of ACL remnants, and present in high concentrations in women undergoing first carpometacarpal arthroplasty. Additionally, RXFP expression is primed by estrogen and progesterone (Table 2).

\section{General Functional and Physiologic Properties of Relaxin}

Relaxin is a controller of ECM turnover, upregulating MMP-1/13 (collagenases) and MMP-2/-9 (gelatinases) to degrade existing collagen while suppressing synthesis of new collagen. Poor collagen quality in the target tissues, along with a lesser amount of proximate total collagen, are the result of these complementary actions of relaxin; illustrated in Figure 2.

\section{KEY REFERENCE ONE: ROLES OF MATRIX METALLOPROTEINASES}

Relaxin modulates many of its effects via MMPs, whose roles were detailed in a 2011 review article by Klein et al. (31) MMP-1 uniquely degrades triple-helical (fibrillar) collagen, leaving it susceptible to gelatinases. Dysregulation causes insufficient or excessive tissue regeneration. MMP-13, activated by MMP-3, cleaves type II collagen during bone remodeling. Dysfunction has been linked to cartilage destruction in osteoarthritis and rheumatoid arthritis. MMP2 degrades gelatine (denatured collagen) and is constitutively expressed. It has roles in angiogenesis and basement membrane structure. MMP-9 also degrades gelatine and is highly inducible by other MMPs. It signals immune cells and is crucial for endometrial tissue remodeling during the menstrual cycle. MMP-3 degrades numerous ECM proteins and is involved in activation of gelatinases and MMP-13 (31).

\section{SYSTEMIC-MUSCULOSKELETAL EFFECTS OF RELAXIN}

\section{Anterior Cruciate Ligament}

The bulk of literature directly addressing relaxin and sex-specific disparities in musculoskeletal health focuses on incidence of ACL rupture. It has been cited that a combination of neuromuscular/ biomechanical differences and sex-specific hormonal variations 
TABLE 2 | Cellular/molecular effects of relaxin- relevant literature findings.

\begin{tabular}{|c|c|c|}
\hline Subcategory & Author, Year & Findings \\
\hline $\begin{array}{l}\text { Basic Properties } \\
\text { of Relaxin }\end{array}$ & $\begin{array}{l}\text { Goldsmith et al. (23) } \\
\text { Grossman et al. (24) } \\
\text { Lubahn et al. (25) } \\
\text { MacLennan et al. (26) } \\
\text { Powell et al. (27) } \\
\text { Wolf et al. (17) } \\
\text { Wolf et al. (28) }\end{array}$ & $\begin{array}{l}\text { - } \text { Relaxin }\left(R L X^{*}\right) \text { is a peptide hormone in the insulin-like growth factor }\left(\mathrm{IGF}^{\dagger}\right) \text { family } \\
\text { - Men and women have similar serum levels }(400-500 \mathrm{pg} / \mathrm{mL} \text { and } 360-495 \mathrm{pg} / \mathrm{mL}) \text {, with luteal phase peaks in } \\
\text { - } \text { - Oral contraceptives decrease relaxin below a detectable serum level } \\
\text { - The major gene for relaxin in humans is } \mathrm{H} 2 ; \mathrm{H} 2 \text { relaxin binds relaxin family peptide receptor } 1 \text { and } 2 \\
\text { - The corpus luteum produces most relaxin, but synthesis occurs in the endometrium, placenta, breast tissue, } \\
\text { and prostate } \\
\text { - Relaxin is biologically and immunologically active during pregnancy } \\
\text { - The capacity of relaxin to act locally means that serum levels do not always reflect activity }\end{array}$ \\
\hline $\begin{array}{l}\text { Properties of Relaxin } \\
\text { Receptors }\end{array}$ & $\begin{array}{l}\text { Bryant-Greenwood et al. } \\
(29) \\
\text { Dragoo et al. (10) } \\
\text { Kapila et al. (30) } \\
\text { Kleine et al. (31) } \\
\text { MacLennan et al. (26) } \\
\text { Powell et al. (27) }\end{array}$ & 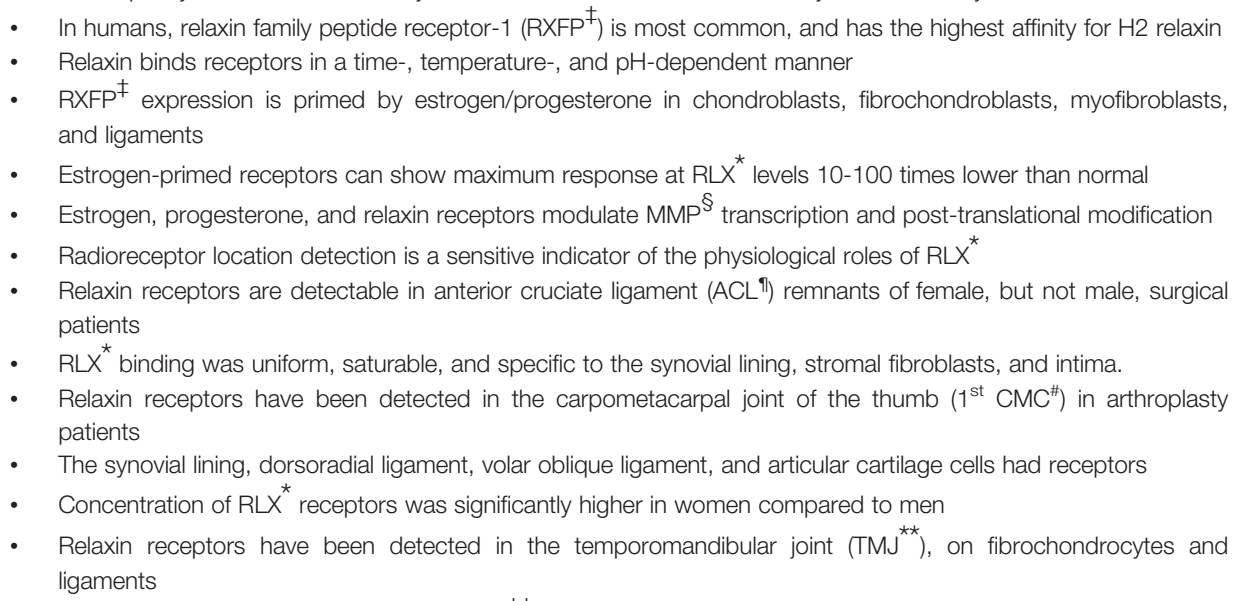 \\
\hline $\begin{array}{l}\text { Functional, } \\
\text { Physiologic }\end{array}$ & $\begin{array}{l}\text { Ando et al. (32) } \\
\text { Dragoo et al. (10) }\end{array}$ & $\begin{array}{l}\text { - Relaxin controls extracellular matrix }\left(\mathrm{ECM}^{\dagger \dagger}\right) \text { turnover by stimulating collagen degradation, and suppressing } \\
\text { synthesis }\end{array}$ \\
\hline Properties of Relaxin & $\begin{array}{l}\text { Galey et al. (33) } \\
\text { Goldsmith et al. (23) } \\
\text { Grossman et al. (24) } \\
\text { Nose-Ogura et al. (13) } \\
\text { Powell et al. (27) }\end{array}$ & 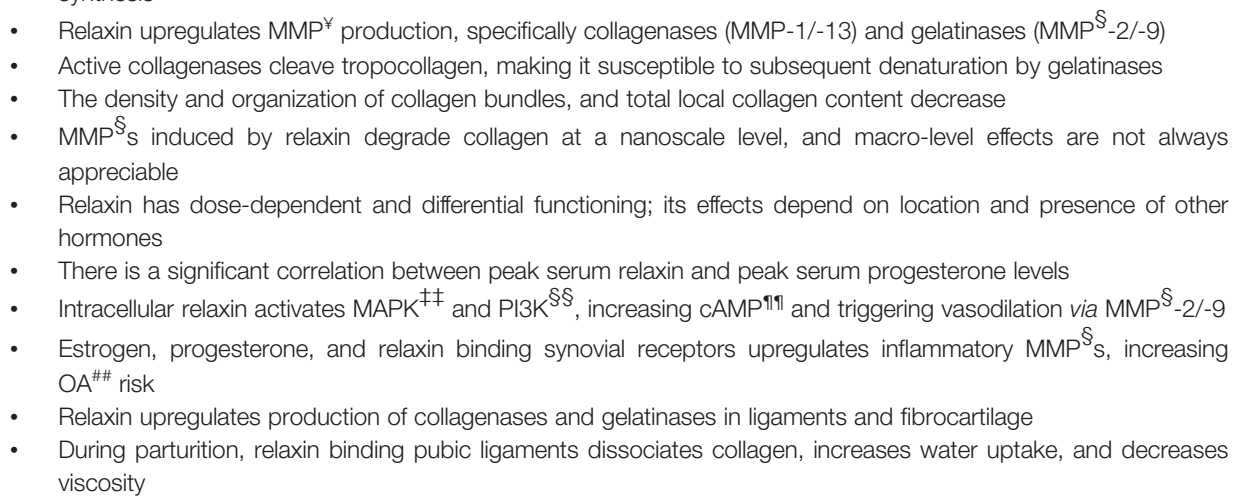 \\
\hline
\end{tabular}

${ }^{*} R L X$, relaxin.

${ }^{\dagger}$ IGF, insulin-like growth factor.

${ }^{\ddagger} R X F P 1$ or 2, relaxin family peptide receptor 1 or 2.

${ }^{\S} M M P$, matrix metalloproteinase.

"ACL, anterior cruciate ligament.

${ }^{*} 1$ st CMC, first/thumb carpometacarpal joint.

${ }^{* *} T M J$, temporomandibular joint.

${ }^{+\dagger} E C M$, extra-cellular matrix.

${ }^{\ddagger \neq}$ MAPK, mitogen-activated phosphate kinase.

§§I3K, phosphoinositide-3-kinase.

"1\% CAMP, cyclic adenosine monophosphate.

\#\# OA, osteoarthritis.

are responsible for the high rate of female ACL injuries. Current injury prevention programs to correct biomechanics have had some success decreasing ACL rupture rates, but a systematic review of prevention program studies concluded that neuromuscular differences alone could not account for the disparity. The female ACL contains receptors for estrogen, progesterone, relaxin, and testosterone, and coupled with the complexity of the hormonal cycle, the authors also noted that single-timepoint hormonal analyses were not depictive (Table 4). Additionally, two studies found that in males, their naturally higher testosterone levels have a protective effect on the ACL, by downregulating collagenolytic activity $(87,88)$. 
TABLE 3 | Musculoskeletal effects of relaxin- relevant literature findings.

\begin{tabular}{|c|c|c|}
\hline Subcategory & Author, Year & Findings \\
\hline $\begin{array}{l}\text { Relaxin and Tendons, } \\
\text { Ligaments of the Leg }\end{array}$ & $\begin{array}{l}\text { Arnold et al. (8) } \\
\text { Brophy et al. (7) } \\
\text { Clifton et al. (34) } \\
\text { Dragoo et al. (1) } \\
\text { Dragoo et al. (9) } \\
\text { Pearson et al. (35) }\end{array}$ & 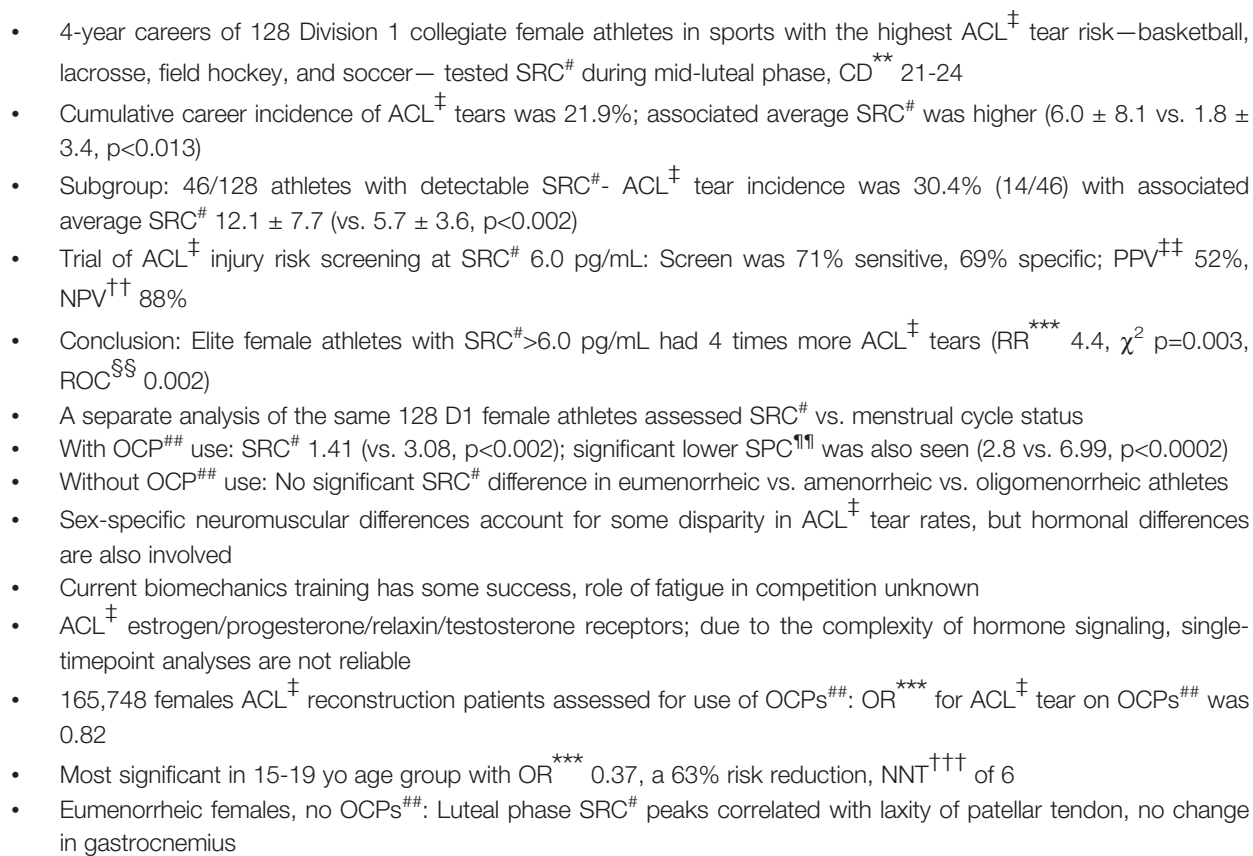 \\
\hline $\begin{array}{l}\text { Relaxin and the Thumb } \\
\mathrm{CMC}^{\S} \text { Joint }\end{array}$ & $\begin{array}{l}\text { Komatsu et al. (36) } \\
\text { Wolf et al. (15) } \\
\text { Wolf et al. (4) }\end{array}$ & $\begin{array}{ll}\text { - } & \mathrm{CMC}^{\S} \text { arthroplasty patients with elevated } \mathrm{SRC}^{\#} \text { expressed increased } \mathrm{RXFP} 1^{\ddagger} \text { in nearby ligaments } \\
\text { - } & \mathrm{RXFP}^{\ddagger} \text { upregulates } \mathrm{MMP1} \rightarrow \text { increases joint laxity, abnormal loading } \\
\text { - } & \mathrm{CMC}^{\S} \text { subluxation risk positively correlates with detectable } \mathrm{SRC}^{\#} \\
\text { - } & \text { Effects of relaxin should be considered during } \mathrm{CMC}^{\S} \text { ligament repairs in women of childbearing age }\end{array}$ \\
\hline $\begin{array}{l}\text { Relaxin and the Jaw, } \\
\text { Mouth }\end{array}$ & $\begin{array}{l}\text { Deniz et al. (14) } \\
\text { Deniz et al. (37) } \\
\text { McGorray et al. (38) }\end{array}$ & 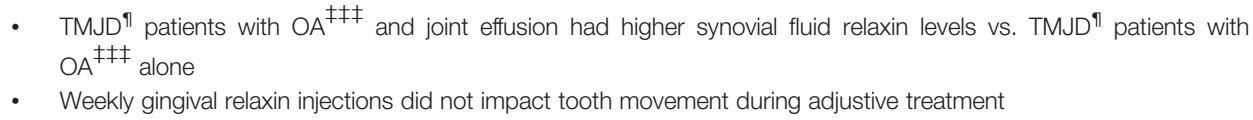 \\
\hline Relaxin and the Shoulder & Owens et al. (39) & $\begin{array}{l}\text { - Military cadets with an episode of acute shoulder instability (47M:6F); were compared to age/sex/height/weight } \\
\text { matched controls } \\
\left.\text { - Those with instability had higher } \mathrm{SRC}^{\#} \text { (3.69 vs. } 2.20, \mathrm{p}=0.02\right) \\
\text { - For every } 1 \mathrm{pg} / \mathrm{mL} \text { increase in } \mathrm{SRC}^{\#} \text { at baseline, cadets were } 2.18 \text { times more likely to have an episode }(95 \% \mathrm{Cl} \\
1.01-4.76)\end{array}$ \\
\hline
\end{tabular}

${ }^{*} R L X$, Relaxin.

${ }^{\dagger}$ RXFP1, RXFP2, Relaxin family peptide receptor $1,2$.

${ }^{\ddagger} A C L(R)$, Anterior cruciate ligament (repair).

$\$_{1}{ }^{\text {st }}$ CMC, First/thumb carpometacarpal joint.

"TMJ(D), Temporomandibular joint disorder.

"SRC, Serum relaxin concentration.

${ }^{* *} \mathrm{CD}$, [Menstrual] cycle day.

${ }^{+t} N P V$, Negative predictive value.

${ }^{\ddagger \ddagger} P P V$, Positive predictive value.

${ }^{\S} R O C$, Receiver operator curve.

"I\% SPC, Serum progesterone concentration.

\#\#OCP, Oral contraceptive.

${ }^{* * *} O R / R R$, Odds ratio, risk ratio.

${ }^{t+t} N N T$, Number needed to treat.

${ }^{\ddagger \ddagger} \mathrm{OA}$, Osteoarthritis.

ACL tear incidence in elite female athletes is as high as $21.9 \%$, as demonstrated in a study which included nearly 130 Division 1 (D1) female collegiate athletes during their 4-year careers in sports with a high risk of ACL injury: basketball, lacrosse, field hockey, and soccer. The athletes underwent SRC testing during the midluteal phase of their menstrual cycle (day 21-24), which showed significantly higher average SRC among athletes who had, or would, suffer ACL tears (6.0 \pm 8.1 vs. $1.8 \pm 3.4, \mathrm{p}<0.013)$ (Table 3).
Given that SRCs are not always detectable, a subgroup of the 46 athletes with detectable mid-luteal SRC were analyzed. The ACL tear incidence of this subgroup was 30.4\% (14/46). Average SRC of injured athletes was $12.1 \pm 7.7$, vs. $5.7 \pm 3.6$ in those without injury $(\mathrm{p}<0.002)$. Among this group, researchers trialed an SRC of $6.0 \mathrm{pg} / \mathrm{mL}$ as the cutoff level for ACL injury risk screening. This screen proved to be $71 \%$ sensitive and $69 \%$ specific, with a PPV of $52 \%$ and an NPV of $88 \%$. Researchers 
TABLE 4 | Pelvic and hip joint related effects of relaxin- relevant literature findings.

Subcategory Author, Year Findings
\begin{tabular}{lll}
\hline Relaxin and the Pubic & MacLennan et al. (40) & 135 women with pubic symphysis disorder $\left(\right.$ SPD $\left.^{\star}\right)$ had $_{\text {SRC }}^{\dagger}$ above the $95 \%$ percentile for an average female \\
Symphysis & MacLennan et al. (41) & population
\end{tabular} Schuster et al. (21) • Infants with $\mathrm{DDH}^{\ddagger}$ born to mothers with $\mathrm{PS}^{\S}$ instability will also have PS ${ }^{\S}$ instability on exam

- Pubic symphysis: Fibrocartilaginous joint, supported by symphyseal ligaments, arcuate ligaments between inferior pubic rami, posterior sacral ligaments, and iliolumbar ligaments-outside of pregnancy, takes 2600 Ibs of force to separate

Relaxin and Uterine Ligaments

Relaxin Peripartum

Relaxin Postpartum

Relaxin and Maternal Factors Impacting $\mathrm{DDH}^{\ddagger}$

Relaxin and Fetal Factors Impacting $\mathrm{DDH}^{\ddagger}$
Kieserman-Schmokler et al. (42)

Reisenauer et al. (43) Schott et al. (44) Uden et al. (45)

Bookhout et al. (46) Kristiansson et al. (47) Ritchie et al. (48) Saugstead et al. (49)

- Uterine prolapse patients have significantly higher $\mathrm{SRC}^{\dagger}, \mathrm{R} 2$ in uterosacral ligaments-modulated by oxytocin and relaxin

- $\quad$ Female infants with $\mathrm{DDH}^{\ddagger}$ have an 11.2 times higher inguinal hernia risk in their first 3 months of life; have surgery earlier (1 mo vs. 10 mo)

- $\quad$ Of all operations on female infants $<3$ mo of age for inguinal hernias, $25 \%$ have $\mathrm{DDH}^{\ddagger}$

- $\quad$ Pregnant women with pelvic pain and pelvic joint instability (PPPJI) were diagnosed earlier if multiparous, prior $\mathrm{OCP}^{\#}$ use

- $\quad$ Severe PPPJI symptoms in the $3^{\text {rd }}$ trimester correlated with higher $\mathrm{SRC}^{\dagger}$

- $\quad$ Infants of PPPJI mothers tended to be post-term, higher weight, and female; 25 in $1000 \mathrm{had} \mathrm{DDH}^{\ddagger}$

- $25 \%$ of women will have disabling musculoskeletal pain of the pelvis/low back at some point during pregnancy

- $\quad$ Primigravid women had a significant positive correlation between $\mathrm{SRC}^{\dagger}$ and pelvic/back pain, stratified at 36 weeks

- $\quad \mathrm{SRC}^{\dagger}<420: 20 \%$ had lumbosacral and $\mathrm{PS}^{\S}$ pain

- $\quad$ SRC $^{\dagger}$ 420-890: 45\% had lumbosacral and PS ${ }^{\S}$ pain

- $\quad \mathrm{SRC}^{\dagger}>890$ : 55\% had lumbosacral and $\mathrm{PS}^{\S}$ pain, $10 \%$ had greater trochanteric pain

- $\quad$ SPD $^{\star}$ occurs in 1/36 pregnancies; worse PS ${ }^{\S}$ pain correlates with more PS ${ }^{\S}$ separation; acute PS ${ }^{\S}$ disruption risk is 1:300-1000

Borg-Stein et al. (50) - Women with higher $\mathrm{SRC}^{\dagger}$ during pregnancy take significantly longer to recover

Leadbetter et al. (51)

- Postpartum relaxin does not return to baseline until 4-12 weeks; injury risk remains elevated; leg and foot pain twice as likely

Andren et al. (18)

Bracken et al. (52)

Forst et al. (53)

MacLennan et al. (19)

Roof et al. (54)

- If the uterine wall does not put normal pressure on the femoral head/acetabular socket interface, $\mathrm{DDH}^{\ddagger} \mathrm{occurs}$

- Two studies found that maternal SPD ${ }^{\star}$ increased infant $\mathrm{DDH}^{\ddagger}$ risk five-fold; one postulated a genetic susceptibility to relaxin

- $\quad$ A majority of $\mathrm{DDH}^{\ddagger}$ infants had primigravid mothers; risk is also increased in twin births, (monozygotic>dizygotic)

- A sibling with $\mathrm{DDH}^{\ddagger}$ increases risk 4.3-14\%, while a parent with $\mathrm{DDH}^{\ddagger}$ increases risk $1.6-2.3 \%$

- No association between cord blood $\mathrm{SRC}^{\dagger}$ and $\mathrm{DDH}^{\ddagger}$ diagnosis; in two studies $\mathrm{DDH}^{\ddagger}$ infant cord blood $\mathrm{SRC}^{\dagger}$ was mildly lower

- $\quad$ Lower maternal relaxin was theorized to decrease laxity of the birth canal

- $\mathrm{DDH}^{\ddagger}$ risk factors, research supported: breech, family history, firstborn, oligohydramnios, high birth weight, postmaturity

Bracken et al. (52)

Forst et al. (53)

Morey et al. (20)

Rhodes et al. (55)

Roof et al. (54)

Schuster et al. (21)

Uden et al. (45)

Relaxin and Neonatal Andren et al. (18)

Findings

Bracken et al. (52)

Uden et al. 45)

- However, 73-90\% of infants with $\mathrm{DDH}^{\ddagger}$ have no identifiable risk factors other than female sex

- Female fetuses are more responsive to maternal hormones, but normally metabolizes and excretes them (hepatic metabolism)

- $\mathrm{DDH}^{\ddagger}$ could reflect decreased ability to metabolize/increased sensitivity to hormones

- $\quad$ Neonates with $\mathrm{DDH}^{\ddagger}$ and abnormal estrogen excretion tend to have PS ${ }^{\S}$ instability

- Could be an inborn, possibly hereditary error of estrogen metabolism

- $\mathrm{DDH}^{\ddagger}$ risk, female infants: 19/1000 baseline, 44/1000 with family history, 120/1000 with breech birth; 25/1000 in PPPJI" moms

- $80 \%$ of $\mathrm{DDH}^{\ddagger}$ cases are bilateral, unilateral cases are 4 times more likely to be left sided due to intrauterine positioning

- In a study of $90 \mathrm{DDH}^{\ddagger}$ neonates, a majority of infants had concurrent pelvic instability on exam

- Abnormalities on neonatal hip ultrasound are significantly more likely to spontaneously resolve in males

- Female neonates with $\mathrm{DDH}^{\ddagger}$ have an 11.2 times greater risk of developing an inguinal hernia during their first 3 months of life

*SPD, symphysis pubis dysfunction/pubic symphysis dysfunction.

${ }^{\dagger} \mathrm{SRC}$, serum relaxin concentration.

${ }^{\ddagger} \mathrm{DDH}$, developmental dysplasia of the hip.

§PS, pubic symphysis.

"PPPJI, pelvic pain and pelvic joint instability.

\#OCP, Oral contraceptive. 


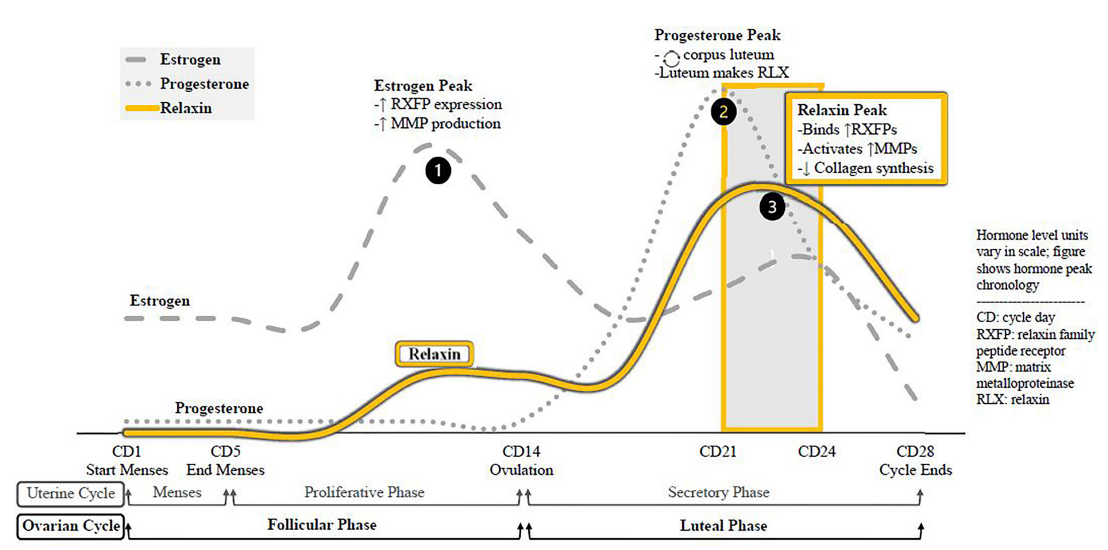

FIGURE 1 | Menstrual cycle hormone peaks, molecular effects. The sequence of hormone peaks for ovulatory cycles. Estrogen levels peak first, increasing expression of relaxin receptors in the body and increasing global synthesis of MMPs. The drop in estrogen triggers ovulation, and the remains of that ovarian follicle from the corpus luteum. As a temporary endocrine body, the corpus luteum secretes progesterone to prepare the endometrium for pregnancy and to sustain itself. It also synthesizes and relaxin, which binds receptors and activates. MMPs recently upregulated by estrogen while suppressing de novo collagen synthesis. Relaxin is active during the luteal phase, chiefly CD21-24.

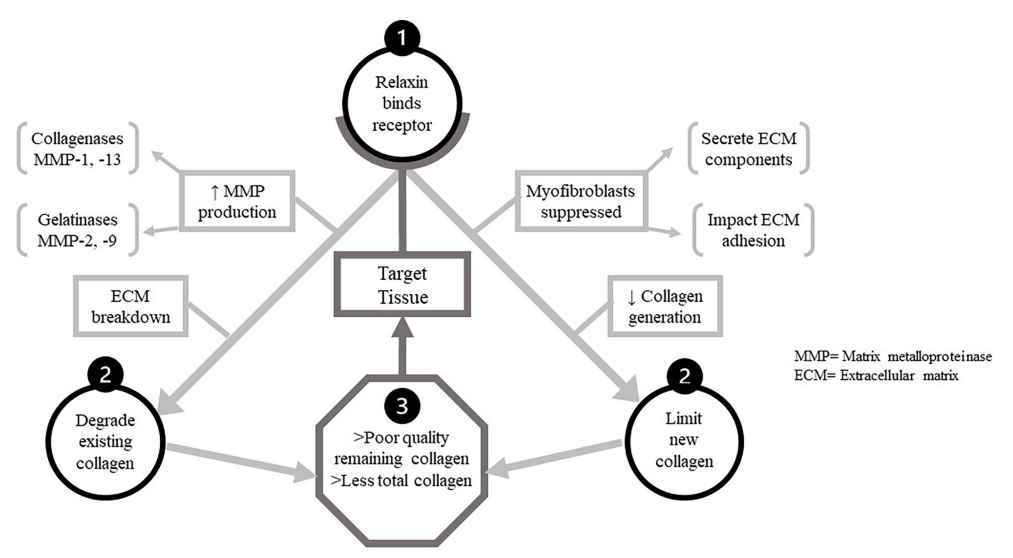

FIGURE 2 | The dual functions of relaxin in target tissues. The two main mechanistic pathways by which relaxin decreases tissue quality and quantity of collagen after binding to its receptor. Upon binding relaxin receptors in target tissue, two processes impacting collagen proceed concurrently. Above, left-relaxin increases production of all MMPs, but particularly the collagenases and gelatinases capable of digesting ECM components. Thus one mechanistic pathway detrimental to target tissue collagen is the degradation of existing collagen by these. MMPs. Above, right-relaxin also suppresses function of/differentiation into myofibroblasts. These cell secrete multiple ECM components and modulate ECM cross-linkage, allowing relaxin to impair de novo collagen synthesis is target tissue.

concluded that elite female athletes with SRC>6.0 pg/mL had a 4 -fold increased risk of an ACL tear during their career (RR 4.4, $\chi^{2} \mathrm{p}=0.003$, ROC $=0.002$ ) (Table 3).

This group of D1 athletes was also surveyed about oral contraceptive pill (OCP) use, to assess potential effects on SRC and ACL tears. It was found that athletes taking OCPs had significantly lower average SRC $(1.41$ vs $3.08, \mathrm{p}<0.002)$ and average serum progesterone concentration (SPC) (2.8 vs. 6.99, $\mathrm{p}<0.0002)$. Interestingly, SRC was not significantly different between eumenorrheic, amenorrheic, and oligomenorrheic athletes. While this cohort study showed that OCPs significantly reduce SRC, a database review of nearly 170,000 female ACL reconstructions showed that OCP also reduced the likelihood of an ACL tear (0.82). This was most significant among 15-19 year-olds, with likelihood of an ACL tear decreasing by $63 \%$ (OR 0.37 ). Analyzing OCPs as a preventive treatment for ACL tears in this age group yielded an NNT of 6 adolescent athletes (Table $\mathbf{3}$ ).

\section{First CMC Joint (Trapeziometacarpal Joint)}

First CMC arthroplasty is a common procedure among women. Studies of first CMC instability and degeneration found the risk of subluxation to be positively correlated with detectable SRC. Immunohistochemical studies of tissue from arthroplasty patients with elevated average SRC showed increased expression of the relaxin receptor RXFP1 in nearby ligaments 
subsequently increasing collagen degradation leading to increased CMC laxity and abnormal weight loading (Table 3).

\section{Other Musculoskeletal Tissues}

Patients with temporomandibular joint disorder (TMJD), another female-predominant condition, showed higher average synovial fluid relaxin levels in those with TMJ OA plus joint effusion, rather than $\mathrm{OA}$ alone. Shoulder instability, an issue common in young female athletes playing overhead sports, was assessed in a cohort study of 53 military cadets (47 male, 6 female) with episodes of acute shoulder instability. Compared to controls matched for age, sex, height, and weight, these 53 cadets had significantly higher SRC (3.69 vs. $2.20, \mathrm{p}=0.02)$. Risk of an acute instability episode vs. SRC had a dose-dependent correlation; every $1 \mathrm{pg} / \mathrm{mL}$ increase in baseline SRC making acute instability 2.18 times more likely (95\% CI 1.014.76) (Table 3).

\section{PELVIC STRUCTURE-SPECIFIC EFFECTS OF RELAXIN}

\section{Pubic Symphysis}

The fibrocartilaginous pubic symphysis joint is stabilized by a combination of symphyseal ligaments, arcuate ligaments between inferior pubic rami, posterior sacral ligaments, and iliolumbar ligaments. Normally, this joint takes 2600 lbs of force to separate; but during late pregnancy and parturition, relaxin triggers enough collagen degradation for separation to occur at much lower forces. In women with the musculoskeletal/ genitourinary symptoms of symphysis pubis dysfunction (SPD) their average SRC was above the 95th percentile for average SRC distribution among age and sex matched controls (Table 4).

\section{Uterine/Pelvic Ligaments}

Relaxin and oxytocin modulate the integrity of uterosacral ligaments, and uterine prolapse patients had significantly higher SRC versus controls, as well as significantly increased RL-2 in ligament samples from prolapse patients vs. control patients undergoing gynecologic surgery. Even prior to puberty relaxin impacts pelvic soft tissues. During the first three months of life, female infants with developmental hip dysplasia (DDH), theorized to have an associated with excess relaxin, have an 11.2 times greater risk of developing an inguinal hernia, and tend to require earlier surgical repairs ( $1 \mathrm{mo}$ vs. $10 \mathrm{mo}$ ). Of all female infants less than 3 months old who require operative intervention for inguinal hernias, 25\% have DDH (Table 4).

\section{Peripartum Pubic Symphysis, Lumbosacral Joints}

A study of pregnant women with pelvic pain and pelvic joint instability (PPPJI) found earlier onset and increased severity in patients with a history of OCP use (exogenously lowered relaxin) and for multiparous women (prior pelvic ligament degradation). Those with severe $3^{\text {rd }}$ trimester symptoms had significantly higher SRC. Their infants tended to be post-term, higher weight, and female; and approximately 25/1000 had DDH. A study of primigravid women at 36 weeks recorded pain incidence and location stratified by mean SRC. Of women with low SRC ( $<420 \mathrm{pg} / \mathrm{mL}), 20 \%$ had lumbosacral and PS pain. In women with moderate SRC (420-890 pg/mL), 45\% had this pain, and which bothered $55 \%$ of women with high SRC (>890 pg/mL); $10 \%$ of whom also had greater trochanteric pain. Research found that $25 \%$ of pregnant women will at some point experience disabling musculoskeletal pain of spine and/or pelvis.

\section{Postpartum Pelvic Recovery}

Women with higher peripartum SRC took longer to recover from childbirth. Relaxin does not return to baseline SRC until 412 weeks postpartum, and women are 2 times more likely to have leg and foot pain secondary to pelvic instability during this period (Table 4).

\section{HIP-SPECIFIC EFFECTS OF RELAXIN}

\section{Fetal Factors Related to DDH}

DDH has well-defined risk factors, including breech delivery, female sex, family history, firstborn status, high birth weight, and post-maturity. However, $73-90 \%$ of infants with DDH have no identifiable risk factor other than female sex; generating the hypothesis that female fetuses are more susceptible to maternal hormones. In normal physiological states, the fetal liver will metabolize these hormones. This is one potential "problem point" leading to $\mathrm{DDH}$; if the fetus has decreased metabolic abilities or increased hormonal sensitivity. Given that neonates with abnormal estrogen excretion and DDH commonly have PS instability on exam, an inborn and possibly hereditary error of estrogen metabolism could be a contributing factor (Table 4).

\section{Maternal Factors Related to DDH}

In utero, if the maternal uterine wall does not put normal pressure on the fetal femoral head/acetabular socket interface, $\mathrm{DDH}$ results. If pregnant women have persistent pelvic/PS pain, their infants have a 5 times increased risk of DDH. The risk of $\mathrm{DDH}$ for female infants at baseline was listed at 19:1000 ("normal" risk of DDH varied by source, but generally ranged between 14-20:1000). Per SPD research, women with more pelvic pain during pregnancy likely have significantly increased SRC, and as previously discussed studies of mothers with SSPJI, symptomatic SPD in pregnancy increases $\mathrm{DDH}$ risk to approximately 25:1000 (Table 4).

Primigravid mothers and those with multiple gestation pregnancies, monozygotic more than dizygotic, have an increased risk of neonate DDH. No significant association has been established between cord blood SRC and incidence of DDH; two studies in this review noted insignificantly lower SRC in cord blood of infants with SRC. It was not known if this could be secondary to inadequate relaxation of the birth canal; or if cord blood SRC was not useful to analyze in this situation given the known local effects of relaxin (Table 4). 


\section{Physical Findings Indicating Excess Relaxin in Neonates with DDH}

A study of 90 neonates with DDH detected concurrent pelvic instability on physical exam in a majority of neonates. Abnormalities detected on neonatal hip ultrasound were significantly more likely to spontaneously resolve in male infants. Additionally, further supporting the theory of pelvic effects of relaxin, female neonates with DDH have an 11.2 times greater risk of developing an inguinal hernia during the first three months of life (Table 4).

\section{KEY REFERENCE TWO: METABOLISM OF CELLS OF THE ACETABULAR LABRUM}

A critical scientific component linking known actions of relaxin to a potential impact on hip health is research by Dhollander et al (89) exploring the cellular metabolism of human acetabular labral cells. Analysis was performed on articular and capsular side labral cells, articular chondrocytes, and meniscal cells (fibrochondrocytes). Labral cells had a number of properties similar to meniscal fibrochondrocytes, such as high COL1A1 levels and ECM turnover in response to increased IL-1 (89).

In labral cells, IL-1 triggers ECM degradation via secretion of IL-6, MMP-1/-2/-3/-9/-13, and ADAMTS-4/-5, while suppressing COL1A1 and COL2A1 expression. The secreted MMPs, ADAMTSs, and IL-6 are known to increase systemic cartilage damage and joint inflammation. Labral cells are unique in their increased MMP-9 expression after exposure to IL-1; MMP-9 is an inducible gelatinase which specifically degrades type IV and V collagen (89).

\section{SUMMARY OF APPRAISED INFORMATION: FACTORS RELATED TO RELAXIN AND HIP INJURIES}

One aim of this scoping review is to show that it is scientifically logical that a correlation would exist between relaxin levels and the high incidence of soft tissue hip injuries in women. This review appraised available information on factors related to the issue of interest. To derive an abridged synopsis of the topics covered, it is helpful to revisit the comparatively large pool of literature that is available which addresses relaxin vs. ACL tears at the micro and macro level.

Beginning at the macro level, numerous studies correlate increased SRC with increased incidence of ACL tear. Conversely, decreasing SRC with OCPs decreased incidence of ACL tears. The impact of relaxin on the ACL during the menstrual cycle is facilitated by preceding estrogen and progesterone peaks which prime target tissues. Relaxin impacts only female ACLs, which display relaxin receptors with specific and saturable binding. Conversely, male ACLs display no relaxin receptors. This binding increases the susceptibility of the ACL to macro-physiologic injury, because micro-physiologic collagen degradation is upregulated while de novo synthesis is suppressed.

Beginning at the micro level for relaxin vs. hip soft tissue injuries, it is known that pelvic ligaments normally have a uniform distribution of relaxin receptors, and the receptor and hormone levels significantly increase in pathologic states such as uterine prolapse. It is also known that acetabular labral cells can be induced to express collagen-degrading MMPs while suppressing deposition of new collagen. The response is unique in the high expression levels of MMP-9; an inducible gelatinase crucial in the female reproductive system for endometrial remodeling during menstruation and basement membrane degradation capacity. MMP-9 is also well-known among pulmonologist for destroying a serine protease inhibitor, facilitating tissue breakdown at inflammatory sites.

The labral cells are adjacent to the ovaries, where the recurring corpus luteum synthesizes large amounts of the paracrine hormone relaxin during the mid-luteal phase. Relaxin remodels endometrial tissue, acting via MMP-9, expression of which also peaks just after ovulation. Relaxin modulates tissue dissolution by stimulating collagenases (MMP-1/-13) and gelatinases (MMP-2/-9); MMPs expressed by labral cells, particularly MMP-9.

Therefore, since relaxin acts in a paracrine fashion, it would be predicted to act throughout the female pelvis during the luteal phase. Due to the presence of relaxin receptors on uterosacral ligaments, ligament laxity would occur. If relaxin has receptors on the neighboring acetabular labral tissue, binding will also trigger collagen turnover via MMP-1/-2/-3/-9/-13 and other components. Labral cells have inducible high expression of MMP-9, which is upregulated in luteal phase reproductive tissue, implicating a large potential role for MMP-9 in relaxininduced degradation of the acetabular labrum. The trio of known molecular components-MMP-9 properties, relaxin properties, and, recently, the metabolism of labral cells-hypothetically working in reciprocal and mutual ways to target the collagen of the acetabular labrum is detailed in Figure 3.

As seen in women with SPD, the micro level degradation of ligaments from high relaxin resulted in macro level instability of the pelvis. As hypothesized in recent DDH studies, relaxininduced laxity of the pelvis vs. hips is interrelated: mothers with elevated relaxin causing pelvic instability are more likely to give birth to infants with $\mathrm{DDH}$, who also display pelvic instability on early exams. In macro level research of the other ball-and-socket joint in humans-the glenohumeral joint-a significant correlation of increased relaxin levels with acute episodes of instability was found.

In addition to appraising available information on factors relevant to a potential hip injury/relaxin relationship, this scoping review also aimed to identify conceptual gaps for future research. The two main gaps in knowledge/research that were identified are as follows:

\section{CONCEPTUAL GAP 1: DO SOFT TISSUES OF THE FEMOROACETABULAR JOINT RESPOND TO RELAXIN?}

There is, in essence, a "missing arrow" in the hypothetical cascade starting at cyclic relaxin peaks and ending at an increased risk of soft tissue injuries of the hip. It is known that relaxin is synthesized in the 


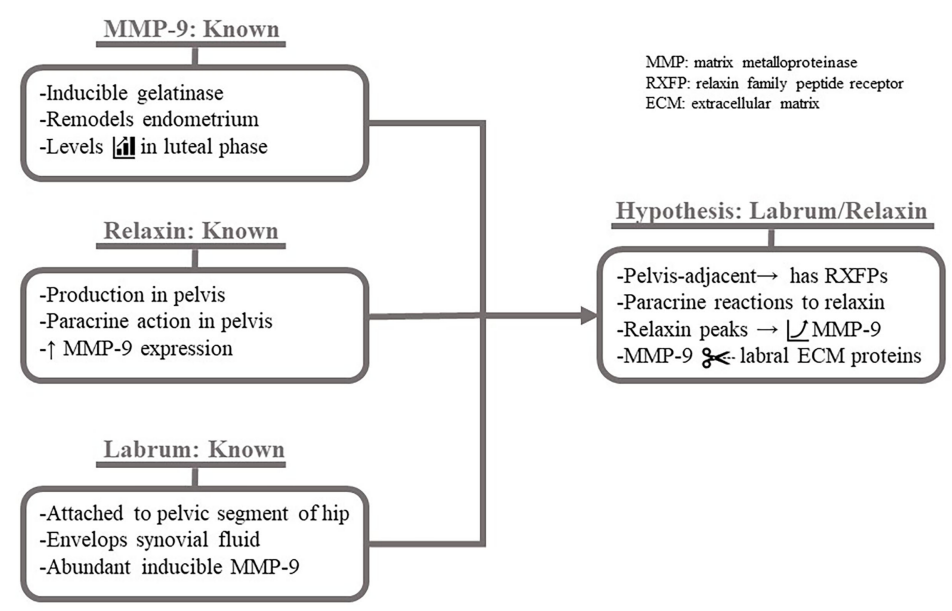

FIGURE 3 | Hypothesized mechanism of relaxin-induced acetabular labrum damage. Known factors giving rise to hypothetical impact of relaxin on the acetabular labrum. It is known that MMP-9 is the inducible gelatinase (MMP-2 is not) which is expressed at high levels during the luteal phase for endometrial. It is known that relaxin, produced in the pelvis and exerting paracrine effects, increases MMP-9 expression. Finally, it is known that the anchored to the pelvis serves as a "seal" enclosing synovial fluid, which may contain hormones, and that the cells express MMP-9 at an unusually high level when induced . Given these known factors: the acetabular labrum likely expresses RXFPs and increases MMP-9 expression in a paracrine to relaxin. MMP-9 degrades ECM proteins, weakening the labrum.

pelvis, has paracrine capabilities, and upregulates expression of the same collagen-degrading MMPs present on the acetabular labrum. What is not known, the "missing link", is whether cells of the acetabular labrum, hip joint synovium, and other soft tissues of the hip joint contain the relaxin receptors necessary to bridge the route from relaxin peaks to increased risk of female hip injuries.

\section{CONCEPTUAL GAP 2: HOW CAN DETRIMENTAL MUSCULOSKELETAL SIDE EFFECTS OF RELAXIN BE COUNTERED?}

It is known that relaxin is crucial for correct function/fertility of the female reproductive tract. Therefore, a theoretical broad "anti-relaxin" would prove harmful. However, it is also apparent that many musculoskeletal effects of relaxin are not physiologically necessary nor desirable, such as hip and knee injuries in female athletes. This presents the question of how to decrease detrimental side effects of relaxin peaks on the musculoskeletal system without causing iatrogenic issues. There are likely multiple avenues by which to approach this issue. Studies in the present review highlight problematic effects of relaxin, but also bring up potential mitigating factors, such as OCP use and menstrual cycle tracking.

\section{LIMITATIONS}

Due to the veritable absence of any type of literature discussing women's hip injuries in the context of relaxin, the premise of this review is based entirely on inductive reasoning. Additionally, consideration of lower-level of evidence literature and inconclusive literature was necessary.

\section{SUMMARY OF SCOPING REVIEW}

The present review showed the scientific logic and medical importance of further researching the potential causative role of relaxin in female hip injuries. Appraisal of available information on related factors, and identification of conceptual gaps for future research was completed.

Collectively, the factors examined in this review support the inference that relaxin impacts the female predominance of soft tissue hip injuries. The steps from relaxin peak to increased ACL injury risk are likely highly analogous to the methodology by which relaxin can precipitate hip damage. Relaxin's synthesis in the pelvis and paracrine profile of action support the potential of relaxin/hip interactions.

This review also highlights why relaxin's sex-specific musculoskeletal effects should be a major orthopedic research focus. The first conceptual gap, bridged simply by assessing male vs. female hip tissue for relaxin receptors, could show a femalespecific, predictable susceptibility to devastating lower extremity injuries. Subsequently, multiple considerations for the second conceptual gap, attenuating relaxin-associated musculoskeletal damage in women, would be critical to explore in order to provide quality, equitable orthopedic care to male and female patients.

\section{CONCLUSION}

Menstrual cycle peaks of relaxin activate MMPs, which locally degrade collagen and gelatine. Women have relaxin receptors in multiple joints, and increased relaxin correlates with increased musculoskeletal injuries. Relaxin has paracrine effects in the female pelvis on ligaments adjacent to hip structures, such as 
acetabular labral cells and hip capsule/synovial cells which express high levels of relaxin-targeted MMPs. Therefore, it is imperative to investigate the effect of relaxin on the hip to determine if increased levels of relaxin are associated with an increased risk of acetabular labral tears.

\section{DATA AVAILABILITY STATEMENT}

The original contributions presented in the study are included in the article/Supplementary Material. Further inquiries can be directed to the corresponding author.

\section{AUTHOR CONTRIBUTIONS}

Per the International Committee of Medical Journal Editors Recommendations for the Conduct, Reporting, Editing, and Publication of Scholarly Work in Medical Journals (ICMJE) Recommendations 2019. EP-author, per ICMJE 2019 recommendations. AM-author, per ICMJE 2019 recommendations. JG-author, per ICMJE 2019 recommendations. MW - author, per ICMJE 2019 recommendations. RW-author, per ICMJE 2019 recommendations. JB-contributor, per ICMJE 2019 recommendations. EP conceived the original review idea, and presented this idea to AM, JG, MW, and RW to direct further topic exploration and refinement of the review focus. JB advised the authors on the design of the work, providing scoping review information. EP ran preliminary PubMed literature searches before EP, AM, and JB met to tailor the search strings for data acquisition. EP and AM performed preliminary data analysis via the paper screening process, with oversight and input from

\section{REFERENCES}

1. Dragoo JL, Castillo TN, Braun HJ, Ridley BA, Kennedy AC, Golish SR. Prospective Correlation Between Serum Relaxin Concentration and Anterior Cruciate Ligament Tears Among Elite Collegiate Female Athletes. Am J Sports Med (2011) 39(10):2175-80. doi: 10.1177/0363546511413378

2. Narvani AA, Tsiridis E, Kendall S, Chaudhuri R, Thomas P. A Preliminary Report on Prevalence of Acetabular Labrum Tears in Sports Patients With Groin Pain. Knee Surg Sports Traumatol Arthrosc (2003) 11(6):403-8. doi: 10.1007/s00167-003-0390-7

3. Weber AE, Nakata H, Mayer EN, Bolia IK, Philippon MJ, Snibbe J, et al. Return to Sport After Hip Arthroscopy for Femoroacetabular Impingement Syndrome in NCAA Division I Athletes: Experience at a Single Institution. Orthop J Sports Med (2020) 8(5):2325967120918383. doi: 10.1177/ 2325967120918383

4. Wolf JM, Williams AE, Delaronde S, Leger R, Clifton KB, King KB. Relationship of Serum Relaxin to Generalized and Trapezial-Metacarpal Joint Laxity. J Handb Surg Am (2013) 38(4):721-8. doi: 10.1016/ j.jhsa.2013.01.019

5. Wolf JM. The Influence of Ligamentous Laxity and Gender: Implications for Hand Surgeons. J Handb Surg Am (2009) 34(1):161-3. doi: 10.1016/ j.jhsa.2008.09.012

6. Sung JK, Akelman E. Thumb Carpometacarpal Arthritis. Tech Orthop (2009) 24(1):23-6. doi: 10.1097/BTO.0b013e3181a07f4c

7. Brophy RH, Silvers HJ, Mandelbaum BR. Anterior Cruciate Ligament Injuries: Etiology and Prevention. Sports Med Arthroscopy Rev (2010) 18 (1):2-11. doi: 10.1097/JSA.0b013e3181cdd195
JG, MW, and RW with regard to screening directions, such as inclusion or exclusion of animal-only subjects. EP and AM then performed more detailed analysis of included studies and interpretation of the charting results, with guidance from JG, MW, and RW on matters such as appropriate categories into which data could be grouped and assessed (i.e. the musculoskeletal effects of relaxin category). EP and AM drafted the manuscript, with significant changes to manuscript organization implemented by JG, MW, and RW. All authors then continued to revise the manuscript until, by consensus, each gave the current version final approval for publication. All authors agree to be held accountable for accuracy and integrity of the work.

\section{ACKNOWLEDGMENTS}

The authors would like to thank Dr. Michael Haugsdal in the Department of Obstetrics and Gynecology for his review of the accuracy of Figure 1; depicting the general chronology of menstrual cycle hormone peaks in a eumenorrheic woman. The authors would also like to thank Jennifer DeBerg from the Hardin Library of Health Sciences for her assistance and expertise in refining search strategies. There was no source of funding for this study.

\section{SUPPLEMENTARY MATERIAL}

The Supplementary Material for this article can be found online at: https://www.frontiersin.org/articles/10.3389/fendo.2022. 827512/full\#supplementary-material

8. Arnold C, Van Bell C, Rogers V, Cooney T, Arnold C, Van Bell C, et al. The Relationship Between Serum Relaxin and Knee Joint Laxity in Female Athletes. Orthopedics (2002) 25(6):669-73. doi: 10.3928/0147-7447-20020601-18

9. Dragoo JL, Castillo TN, Korotkova TA, Kennedy AC, Kim HJ, Stewart DR. Trends in Serum Relaxin Concentration Among Elite Collegiate Female Athletes. Int J Womens Health (2011) 3:19-24.

10. Dragoo JL, Lee RS, Benhaim P, Finerman GA, Hame SL. Relaxin Receptors in the Human Female Anterior Cruciate Ligament. Am J Sports Med (2003) 31 (4):577-84. doi: 10.1177/03635465030310041701

11. DeFroda SF, Bokshan SL, Worobey S, Ready L, Daniels AH, Owens BD. Oral Contraceptives Provide Protection Against Anterior Cruciate Ligament Tears: A National Database Study of 165,748 Female Patients. Phys Sportsmed (2019) 47(4):416-20. doi: 10.1080/00913847.2019.1600334

12. Alves de Oliveira J, Marques Simek Vega GonÃ@alves TS, Soares Reis Vilanova L, Maria Bovi Ambrosano G, Rodrigues Garcia RCM. Female Hormones Fluctuation and Chewing Movement of Patients With Disc Displacement. Rev Odonto Ciencia (2012) 27(1):20-5. doi: 10.1590/S198065232012000100004

13. Nose-Ogura S, Yoshino O, Yamada-Nomoto K, Nakamura M, Harada M, Dohi M, et al. Oral Contraceptive Therapy Reduces Serum Relaxin-2 in Elite Female Athletes. J Obstet Gynaecol Res (2017) 43(3):530-5. doi: 10.1111/jog.13226

14. Deniz K, Bascil Tutuncu N, Bayraktar N, Uckan S. Does Hormone Relaxin Have a Potential Role in TMJ Internal Derangements? J Oral Maxillofacial Surg (2012) 70(9):e99-100. doi: 10.1016/j.joms.2012.06.150

15. Wolf JM, Williams AE, King KB. Serum Relaxin is Correlated With Relaxin and Mmp-1 in the Anterior Oblique Ligament Level 3 Evidence. J Hand Surg (2011) 36(8):28. doi: 10.1016/S0363-5023(11)60032-4 
16. Henneman S, Bildt MM, DeGroot J, Kuijpers-Jagtman AM, Von den Hoff JW. Relaxin Stimulates MMP-2 and $\alpha$-Smooth Muscle Actin Expression by Human Periodontal Ligament Cells. Arch Oral Biol (2008) 53(2):161-7. doi: 10.1016/j.archoralbio.2007.08.010

17. Wolf J, Scott F, Etchell E, Williams AE, Delaronde S, King KB. Serum Relaxin is Correlated With Relaxin Receptors and MMP-1 in the Anterior Oblique Ligament. Osteoarthr Cartil (2012) 20:S250. doi: 10.1016/j.joca. 2012.02.416

18. Andren L. Pelvic Instability in Newborns With Special Reference to Congenital Dislocation of the Hip and Hormonal Factors. A Roentgenol Study Acta Radiol Suppl (1962) 212:1-66.

19. Maclennan AH, Maclennan SC. Symptom-Giving Pelvic Girdle Relaxation of Pregnancy, Postnatal Pelvic Joint Syndrome and Developmental Dysplasia of the Hip. Acta Obstetricia Gynecol Scandinavica (1997) 76(8):760-4. doi: 10.3109/00016349709024343

20. Morey SS. AAP Develops Guidelines for Early Detection of Dislocated Hips. Am Family Physician (2001) 63(3):565-8.

21. Schuster RO, Port M. Abnormal Pronation in Children. An Hormonal Etiology. J Am Podiatry Assoc (1977) 67(9):613-5. doi: 10.7547/8750731567-9-613

22. Munn Z, Peters MDJ, Stern C, Tufanaru C, McArthur A, Aromataris E. Systematic Review or Scoping Review? Guidance for Authors When Choosing Between a Systematic or Scoping Review Approach. BMC Med Res Methodol (2018) 18(1):143. doi: 10.1186/s12874-018-0611-x

23. Goldsmith LT, Weiss G, Steinetz BG. Relaxin and Its Role in Pregnancy. Endocrinol Metab Clin North Am (1995) 24(1):171-86. doi: 10.1016/S08898529(18)30058-6

24. Grossman J, Frishman WH. Relaxin: A New Approach for the Treatment of Acute Congestive Heart Failure. Cardiol Rev (2010) 18(6):305-12. doi: 10.1097/CRD.0b013e3181f493e3

25. Lubahn J, Ivance D, Konieczko E, Cooney T. Immunohistochemical Detection of Relaxin Binding to the Volar Oblique Ligament. J Handb Surg Am (2006) 31(1):80-4. doi: 10.1016/j.jhsa.2005.09.012

26. MacLennan AH. The Role of Relaxin in Human Reproduction. Clin Reprod Fertil (1983) 2(2):77-95.

27. Powell BS, Dhaher YY, Szleifer IG. Review of the Multiscale Effects of Female Sex Hormones on Matrix Metalloproteinase-Mediated Collagen Degradation. Crit Rev BioMed Eng (2015) 43(5-6):401-28. doi: 10.1615/CritRevBiomedEng. 2016016590

28. Wolf JM, Cameron KL, Clifton KB, Owens BD. Serum Relaxin Levels in Young Athletic Men Are Comparable With Those in Women. Orthopedics (2013) 36(2):128-31. doi: 10.3928/01477447-20130122-06

29. Bryant-Greenwood GD, Mercado-Simmen R, Yamamoto SY, Arakaki RF, Uchima FD, Greenwood FC. Relaxin Receptors and a Study of the Physiological Roles of Relaxin. Adv Exp Med Biol (1982) 143:289-314. doi: 10.1007/978-1-4613-3368-5_27

30. Kapila S, Xie Y. Targeted Induction of Collagenase and Stromelysin by Relaxin in Unprimed and $\beta$-Estradiol-Primed Diarthrodial Joint Fibrocartilaginous Cells But Not in Synoviocytes. Lab Invest (1998) 78(8):925-38.

31. Kleine SA, Budsberg SC. Synovial Membrane Receptors as Therapeutic Targets: A Review of Receptor Localization, Structure, and Function. J Orthop Res (2017) 35(8):1589-605. doi: 10.1002/jor.23568

32. Ando H, Moriwaki C. Studies on Relaxin Assay With X-Ray Photography. Endocrine J (1960) 7:167-70. doi: 10.1507/endocrj1954.7.167

33. Galey S, Konieczko EM, Arnold CA, Cooney TE. Immunohistological Detection of Relaxin Binding to Anterior Cruciate Ligaments. Orthopedics (2003) 26(12):1201-4. doi: 10.3928/0147-7447-20031201-08

34. Clifton K, Rodner CM, Drissi H, Wolf JM. Detection of Relaxin Receptor in the Synovium and Dorsoradial Ligament of the Trapeziometacarpal Joint: Not a Clinical Study. J Handb Surg (2012) 37(8):7. doi: 10.1016/S0363-5023(12) 60010-0

35. Pearson SJ, Burgess KE, Onambélé GL. Serum Relaxin Levels Affect the In Vivo Properties of Some But Not All Tendons in Normally Menstruating Young Women. Exp Physiol (2011) 96(7):681-8. doi: 10.1113/expphysiol. 2011.057877

36. Komatsu I, Lubahn JD. Anatomy and Biomechanics of the Thumb Carpometacarpal Joint. Operative Techniques Orthopaedics (2018) 28(1):15. doi: $10.1053 /$ j.oto.2017.12.002
37. Deniz K, Guler N, Bascil Tutuncu N, Uckan S. Analysis of Hormone Relaxin in the Synovial Fluid of Patients With Temporomandibular Disorders. Int J Oral Maxillofacial Surg (2013) 42(10):1359. doi: 10.1016/j.ijom.2013.07.672

38. McGorray SP, Dolce C, Kramer S, Stewart D, Wheeler TT. A Randomized, Placebo-Controlled Clinical Trial on the Effects of Recombinant Human Relaxin on Tooth Movement and Short-Term Stability. Am J Orthod Dentofacial Orthop (2012) 141(2):196-203. doi: 10.1016/j.ajodo.2011.07.024

39. Owens BD, Cameron KL, Clifton KB, Svoboda SJ, Wolf JM. Association Between Serum Relaxin and Subsequent Shoulder Instability. Orthopedics (2016) 39(4):e724-8. doi: 10.3928/01477447-20160421-01

40. MacLennan AH, Nicolson R, Green RC, Bath M. Serum Relaxin and Pelvic Pain of Pregnancy. Lancet (1986) 2(8501):243-5. doi: 10.1016/S0140-6736(86) 92069-6

41. MacLennan AH. The Role of the Hormone Relaxin in Human Reproduction and Pelvic Girdle Relaxation. Scand J Rheumatol Suppl (1991) 88:7-15.

42. Kieserman-Shmokler C, Swenson CW, Chen L, Desmond LM, Ashton-Miller JA, DeLancey JO. From Molecular to Macro: The Key Role of the Apical Ligaments In Uterovaginal Support. Am J Obstetrics Gynecol (2020) 222 (5):427-36. doi: 10.1016/j.ajog.2019.10.006

43. Reisenauer C, Renz M, Busch C, Drews U. Smooth Muscle in the Sacrouterine Ligament is Regulated by Oxytocin and Relaxin: Perfusion of Surgical Samples Under the Microscope. Arch Gynecol Obstetrics (2010) 282:S57. doi: 10.1007/ s00404-010-1632-9

44. Schott S, Reisenauer C, Busch C. Presence of Relaxin-2, Oxytocin and Their Receptors In Uterosacral Ligaments of Pre-Menopausal Patients With and Without Pelvic Organ Prolapse. Acta Obstet Gynecol Scand (2014) 93 (10):991-6. doi: 10.1111/aogs.12462

45. Udén A, Lindhagen T. Inguinal Hernia in Patients With Congenital Dislocation of the Hip. A Sign of General Connective Tissue Disorder. Acta Orthop Scand (1988) 59(6):667-8. doi: 10.3109/17453678809149421

46. Bookhout MM, Boissonnault JS. Musculoskeletal Dysfunction in the Female Pelvis. Orthopaedic Phys Ther Clinics North Am (1996) 5(1):23-45.

47. Kristiansson P, Svardsudd K, Von Schoultz B. Serum Relaxin, Symphyseal Pain, and Back Pain During Pregnancy. Am J Obstetrics Gynecol (1996) 175 (5):1342-7. doi: 10.1016/S0002-9378(96)70052-2

48. Ritchie JR. Orthopedic Considerations During Pregnancy. Clin Obstetrics Gynecol (2003) 46(2):456-66. doi: 10.1097/00003081-200306000-00024

49. Saugstad LF. Persistent Pelvic Pain and Pelvic Joint Instability. Eur J Obstet Gynecol Reprod Biol (1991) 41(3):197-201. doi: 10.1016/0028-2243(91)90024-F

50. Borg-Stein J, Dugan SA. Musculoskeletal Disorders of Pregnancy, Delivery and Postpartum. Phys Med Rehabil Clinics North America (2007) 18(3):45976. doi: 10.1016/j.pmr.2007.05.005

51. Leadbetter RE, Mawer D, Lindow SW. Symphysis Pubis Dysfunction: A Review of the Literature. J Maternal-Fetal Neonatal Med (2004) 16(6):34954. doi: 10.1080/jmf.16.6.349.354

52. Bracken J, Tran T, Ditchfield M. Developmental Dysplasia of the Hip: Controversies and Current Concepts. J Paediatrics Child Health (2012) 48 (11):963-73. doi: 10.1111/j.1440-1754.2012.02601.x

53. Forst J, Forst C, Forst R, Heller KD. Pathogenetic Relevance of the Pregnancy Hormone Relaxin to Inborn Hip Instability. Arch Orthop Trauma Surg (1997) 116(4):209-12. doi: 10.1007/BF00393711

54. Roof AC, Jinguji TM, White KK. Musculoskeletal Screening: Developmental Dysplasia of the Hip. Pediatr Ann (2013) 42(11):229-35. doi: 10.3928/ 00904481-20131022-10

55. Rhodes AM, Clarke NM. A Review of Environmental Factors Implicated in Human Developmental Dysplasia of the Hip. J Child Orthop (2014) 8(5):3759. doi: 10.1007/s11832-014-0615-y

56. Armfield DR, Kim DHM, Towers JD, Bradley JP, Robertson DD. SportsRelated Muscle Injury in the Lower Extremity. Clinics Sports Med (2006) 25 (4):803-42. doi: 10.1016/j.csm.2006.06.011

57. Arya RK. Low Back Pain - Signs, Symptoms, and Management. J Indian Acad Clin Med (2014) 15(1).

58. Braddon SA. The Effects of Relaxin on Cyclic-AMP an Ornithine Decarboxylase Levels in Target Tissues. Adv Exp Med Biol (1982) 143:25572. doi: 10.1007/978-1-4613-3368-5_23

59. Camiel MR. Relaxin and the Radiolucent Fissure in the Symphysis Pubis During Pregnancy: The Gas Phenomenon. Am J Obstetrics Gynecol (1986) 154 (5):1104-5. doi: 10.1016/0002-9378(86)90763-5 
60. Charalambous CP, Morrey BF. Posttraumatic Elbow Stiffness. J Bone Joint Surg Ser A (2012) 94(15):1428-37. doi: 10.2106/JBJS.K.00711

61. Em S, Oktayoglu P, Bozkurt M, Caglayan M, Karakoc M, Ucar D, et al. Serum Relaxin Levels in Benign Hypermobility Syndrome. J Back Musculoskelet Rehabil (2015) 28(3):473-9. doi: 10.3233/BMR-140543

62. Ferlin A, Pepe A, Facciolli A, Gianesello L, Foresta C. Relaxin Stimulates Osteoclast Differentiation and Activation. Bone (2010) 46(2):504-13. doi: 10.1016/j.bone.2009.10.007

63. Gates C, Huard J. Management of Skeletal Muscle Injuries in Military Personnel. Operative Techniques Sports Med (2005) 13(4):247-56. doi: 10.1053/j.otsm.2006.01.012

64. Gould S, Hooper J, Strauss E. Anterior Cruciate Ligament Injuries in Females Risk Factors, Prevention, and Outcomes. Bull Hosp Joint Dis (2016) 74(1):4651.

65. Hamilton DAJr., Wright RDJr., Moghadamian ES, Bruce BT. Orthopaedic Considerations in the Pregnant Patient. Curr Orthopaedic Pract (2012) 23 (6):601-8. doi: 10.1097/BCO.0b013e318264843e

66. Heckman JD, Sassard R. Musculoskeletal Considerations in Pregnancy. J Bone Joint Surg Ser A (1994) 76(11):1720-31. doi: 10.2106/00004623-19941100000018

67. Huston LJ, Greenfield MLVH, Wojtys EM. Anterior Cruciate Ligament Injuries in the Female Athlete: Potential Risk Factors. Clin Orthopaedics Related Res (2000) 372):50-63. doi: 10.1097/00003086-200003000-00007

68. Kapila S, Park Y, Ahmad N, Hosomichi J, Hayami T, Tacon C. Mechanisms for Relaxin's Modulation of MMPs and Matrix Loss in Fibrocartilages. Ital J Anat Embryol (2013) 118(1 SUPPL.):62-5.

69. Marshall-Gradisnik S, Nicholson V, Weatherby R, Bryant A. The Relationship Between Relaxin, Tumour Necrosis Factor Alpha and Macrophage Inflammatory Factor and Monophasic Oral Contraception Pill. J Sci Med Sport (2004) 7(4 Supplement):28-. doi: 10.1016/S1440-2440(04)80102-6

70. Martin B, Romero G, Salama G. Cardioprotective Actions of Relaxin. Mol Cell Endocrinol (2019) 487:45-53. doi: 10.1016/j.mce.2018.12.016

71. Nistri S, Bigazzi M, Bani D. Relaxin as a Cardiovascular Hormone: Physiology, Pathophysiology and Therapeutic Promises. Cardiovasc Hematol Agents Med Chem (2007) 5(2):101-8. doi: 10.2174/187152507780363179

72. Noon ML, Hoch AZ. Challenges of the Pregnant Athlete and Low Back Pain. Curr Sports Med Rep (2012) 11(1):43-8. doi: 10.1249/JSR.0b013e31824330b6

73. Owens K, Pearson A, Mason G. Pubic Symphysis Separation. Fetal Maternal Med Rev (2002) 13(2):141-55. doi: 10.1017/S0965539502000244

74. Pires R, Labronici PJ, Giordano V, Kojima KE, Kfuri M, Barbisan M, et al. Intrapartum Pubic Symphysis Disruption. Ann Med Health Sci Res (2015) 5 (6):476-9. doi: 10.4103/2141-9248.177980

75. Pokorny MJ, Smith TD, Calus SA, Dennison EA. Self-Reported Oral Contraceptive Use and Peripheral Joint Laxity. J Orthop Sports Phys Ther (2000) 30(11):683-92. doi: 10.2519/jospt.2000.30.11.683

76. Ren XF, Zhao H, Gong XC, Wang LN, Ma JF. RLN2 Regulates In Vitro Invasion and Viability of Osteosarcoma MG-63 Cells via S100A4/MMP-9 Signal. Eur Rev Med Pharmacol Sci (2015) 19(6):1030-6.

77. Samuel CS, Unemori EN, Mookerjee I, Bathgate RA, Layfield SL, Mak J, et al. Relaxin Modulates Cardiac Fibroblast Proliferation, Differentiation, and Collagen Production and Reverses Cardiac Fibrosis In Vivo. Endocrinology (2004) 145(9):4125-33. doi: 10.1210/en.2004-0209

78. Sanders AE, Jain D, Sofer T, Kerr KF, Laurie CC, Shaffer JR, et al. GWAS Identifies New Loci for Painful Temporomandibular Disorder: Hispanic Community Health Study/Study of Latinos. J Dent Res (2017) 96(3):277-84. doi: 10.1177/0022034516686562

79. Snith FW, Smith PA. Musculoskeletal Differences Between Males and Females. Sports Med Arthroscopy Rev (2002) 10(1):98-100. doi: 10.1097/ 00132585-200210010-00014
80. Steinetz BG, Manning JP. Influence of Growth Hormone, Steroids and Relaxin on Acid Phosphatase Activity of Connective Tissue. Proc Soc Exp Biol Med Soc Exp Biol Med (New York NY) (1967) 124(1):180-4. doi: 10.3181/00379727124-31695

81. Szalay EA. Sexual Dimorphism in Musculoskeletal Medicine. Eur Musculoskeletal Rev (2012) 7(3):162-4.

82. Toth AP, Cordasco FA. Anterior Cruciate Ligament Injuries in the Female Athlete. J Gend Specif Med (2001) 4(4):25-34.

83. van der MC. Experiments on the Mechanism of Action of Relaxin. Acta Endocrinol (1950) 4(4):325-42. doi: 10.1530/acta.0.0040325

84. Veitia R, Laurent A, Quintana-Murci L, Ottolenghi C, Fellous M, Vidaud M, et al. The INSL4 Gene Maps Close to WI-5527 at 9p24.1 $\rightarrow$ P23.3 Clustered With Two Relaxin Genes and Outside the Critical Region for the Monosomy 9p Syndrome. Cytogenetics Cell Genet (1998) 81(3-4):275-7. doi: 10.1159/ 000015045

85. Warren MP, Fried JL. Temporomandibular Disorders and Hormones in Women. Cells Tissues Organs (2001) 169(3):187-92. doi: 10.1159/000047881

86. Weinberg A. An X-Ray Pelvimetric Study of Relaxin Extract in Pelvic Expansion. Surg Gynecol Obstetr (1956) 103(3):303-6.

87. Freeman BM, Mountain DJ, Brock TC, Chapman JR, Kirkpatrick SS, Freeman $\mathrm{MB}$, et al. Low Testosterone Elevates Interleukin Family Cytokines in a Rodent Model: A Possible Mechanism for the Potentiation of Vascular Disease in Androgen-Deficient Males. J Surg Res (2014) 190(1):319-27. doi: 10.1016/j.jss.2014.03.017

88. Henmi H, Endo T, Nagasawa K, Hayashi T, Chida M, Akutagawa N, et al. Lysyl Oxidase and MMP-2 Expression in Dehydroepiandrosterone-Induced Polycystic Ovary in Rats. Biol Reprod (2001) 64(1):157-62. doi: 10.1095/ biolreprod64.1.157

89. Dhollander AA, Lambrecht S, Verdonk PC, Audenaert EA, Almqvist KF, Pattyn C, et al. First Insights Into Human Acetabular Labrum Cell Metabolism. Osteoarthr Cartil (2012) 20(7):670-7. doi: 10.1016/j.joca. 2012.03.023

Conflict of Interest: All authors have completed the ICMJE uniform disclosure form at www.icmje.org/coi_disclosure.pdf and declare as follows: MW reports personal fees from Depuy Synthes Sales Inc, other from Smith \& Nephew, personal fees from Zimmer Biomet Inc, personal fees from Stryker Corp; outside the submitted work. RW reports personal fees, non-financial support and other from Smith and Nephew, other from Arthrex, personal fees from Medical Device Business Systems, personal fees from Linvatec Corporation, other from Wardlow Enterprises; outside the submitted work.

The remaining authors declare that the research was conducted in the absence of any commercial or financial relationships that could be construed as a potential conflict of interest.

Publisher's Note: All claims expressed in this article are solely those of the authors and do not necessarily represent those of their affiliated organizations, or those of the publisher, the editors and the reviewers. Any product that may be evaluated in this article, or claim that may be made by its manufacturer, is not guaranteed or endorsed by the publisher.

Copyright (๑) 2022 Parker, Meyer, Goetz, Willey and Westermann. This is an openaccess article distributed under the terms of the Creative Commons Attribution License (CC BY). The use, distribution or reproduction in other forums is permitted, provided the original author(s) and the copyright owner(s) are credited and that the original publication in this journal is cited, in accordance with accepted academic practice. No use, distribution or reproduction is permitted which does not comply with these terms. 